\title{
Editorial: Context-based Composition
}

Our first thematic issue, OS 22(1), introduced a body of current work related to the theme of context-based composition, that is, how creative work engages with the 'real world' in terms of its epistemology and design strategies, not merely anecdotally but in a fundamental manner. That issue included articles across a wide range of theoretical and applied topics, including ecological approaches, live performance, installations, mobile and ubiquitous technology, historical examples and interdisciplinary practices.

Here we continue those lines of enquiry, first with Anette Vandsø's discussion of four key concepts for studying this subject, what she refers to as 'paratext, intermediality, enunciation and mediality', concepts that help us to understand how 'compositions establish their relation to a specific context'. She focuses on work that uses technology to capture sounds and/or data from the real world and re-present them to listeners, without necessarily constructing a virtual soundscape. First is the information provided about the work (paratext), plus visual information, for instance (intermediality), an approach illustrated later in the issue by Matilde Meireles in her installations. Drawing on Barthes and Beneviste's concept of enunciation, she discusses how compositional techniques can draw attention to context, directly with speech and indirectly through other actions. Finally, she points to the specific aspects of audio technology (mediality) that are not merely creating inscriptions but act as 'transmissional', to use Douglas Kahn's term (Kahn 2013). Ultimately, she argues that such works draw on our knowledge of the world, and also influence how we understand and talk about that world.

Marinos Koutsomichalis continues the discussion around a set of current practices involving 'material inquiry, anti-optimality, and hybrid, reflexive or "meta" interfaces', as well as collaborative approaches, all of which function outside of the traditional aesthetic paradigm. He interprets the significance of this new ad hoc aesthetics in terms of 'emergence, transience and post-selfhood', traits that emerge from the nature of contemporary media and their networks of communication.

One of the main categories and concerns of the submitted articles has been the environmental and ecological, and in OS 22(1) we presented three overviews of the subject. Here we continue with another three that present specific projects. Brona Martin gives a summary of soundscape-based approaches and discusses various projects that engage directly with communities, such as those undergoing 'regeneration and renewal', often with deleterious effects, as well as those involved in political protest. Teresa Connors and Andrew Denton have a lengthy history of collaboration on environmentally themed projects in various countries, and their article offers nuanced insights into the evolution of their collective practices grounded by being 'in' these environments. Carolyn Philpott provides a comprehensive documentation of the work of sound artist Cheryl Leonard that is based on and in the Antarctic, a touchstone environment related to climate change, and discusses Leonard's efforts to balance the aesthetic with the ethical in her work.

Next, we have two papers that deal with the materiality of real-world contexts, the first by Diogo Alvim who explores the interdisciplinary connections between architectural thinking and practice and music creation, using such concepts as material, site, drawing, programme and use, both historically and in current compositional work. This kind of analysis highlights the need to distinguish the traditional visual approach to space and architecture from the aural experience of 'acoustic space' (Truax 2017) that is implicitly or directly involved in all the compositional work discussed here. Otso Lähdeoja addresses an even more literal form of materiality, namely transmitting sound through physical objects, or what he terms 'materially mediated electronic musicianship'. These two papers, taken together, remind us that sound as vibration is inherently influenced by every stage of transfer of the source excitation to medium of propagation, including the physical space into which it is projected. Although we often refer to the electroacoustically reproduced sound (source) as disembodied, in practice it is just as 'embodied' as acoustic sound.

Organised Sound over the last two decades has established itself as a forum for an emerging musicology of electroacoustic music that has been expanding to include a wider range of concerns and practices. The following articles present three different approaches to the analysis of specific composers' works by authors with musicological and other backgrounds. Erik DeLuca analyses the environmentally inspired work of 
John Luther Adams, asking what concept of 'nature' it represents. He also poses the more incisive question: 'What is self-critical environmental sonic art?', just as Gregg Wagstaff asked, more than 15 years ago, what is acoustic ecology's 'ecology' (Wagstaff 1999), a topic also addressed by Jonathan Gilmurray in the OS 22(1) issue. The call for this issue included gender concerns in composition, a topic that has been consistently raised by Hannah Bosma (2017) with regard to electrovocal music. So, I was somewhat surprised that the only submission in this category was Danielle Sofer's analysis of my own work, Song of Songs (1994). As guest editor, this might seem awkward, but I am pleased it is included, given the scarcity of electroacoustic work concerning sexual identity. As an interesting example of an expanding musicology, Nimalan Yoganathan and Owen Chapman have contributed a fascinating comparison of the Jamaican dub music of King Tubby with the compositional methods of soundscape composers, providing insight into the highly contextual basis for the creation and consumption of a popular form of music that they argue is more innovative than the commercial norms. Whereas popular music studies and ethnomusicology would probably only analyse this music according to its 'style', these authors emphasise its contextual roots.

Finally, we include three practice-based articles that document work from different geographical contexts and artistic approaches. As mentioned earlier, Matilde Meireles extends the phonographic approach to sonic documentation with multi-sensory elements of her installations in Brazil and Belfast. Guillaume Campion and Guillaume Côté describe a musical form of documentary that blends acousmatic techniques with the more traditional sound (or radio) documentary, in this case through their creation of a half-hour piece concerning the Montréal waterfront. Finally, Iain Findlay-Walsh discusses his self-reflexive approach to autoethnography, or what he calls a 'self-narrative' that represents the recordist of the work in the work, not necessarily by running commentary.

Based on these two sets of articles on context-based creation, we might ask what is still missing and where might this type of work lead? Given that there appears to be no limit to what aspects of our world an artist might engage with, it may be risky to suggest any boundary to this emerging genre that seems to inspire a wide range of practitioners. I've mentioned a lack of gender-based approaches, but the real absence is the lack of artistically informed work that deals with broader social issues. Of course, environmental issues, a current concern of many artists today, have been referred to extensively, but the projects in these articles have tended to go in one direction: real-world contexts informing the art, rather than artistic practice being applied to other social issues. This is not surprising since creative artists want to focus on their own work, and in many cases, see it possibly changing listeners' awareness. However, if artists are also sufficiently trained in the science and social science of sound as broadly as possible, their perceptual, musical and technological training may provide them with skills that can be applied to issues broader than purely artistic production. I have argued this point elsewhere in terms of 'acoustic sustainability' (Truax 2012) but there is much more to be explored in this area. Let us hope to see further developments of this topic in future issues of the journal.

Barry Truax (truax@sfu.ca)

\section{REFERENCES}

Bosma, H. 2017. Unsettling Performances, Soundwalks and Loudspeakers: Gender in Electroacoustic Music and Other Sounding Arts. In M. Cobussen, V. Meelberg and B. Truax (eds.) The Routledge Companion to Sounding Art. New York: Routledge.

Kahn, D. 2013. Earth Sound Earth Signal. Berkeley, CA: University of California Press.

Truax, B. 2012. Music, Soundscape and Acoustic Sustainability. Moebius online journal. www.sfu.ca/ $\sim$ truax/newpaper.html.

Truax, B. 2017. Acoustic Space, Community and Virtual Soundscapes. In M. Cobussen, V. Meelberg and B. Truax (eds.) The Routledge Companion to Sounding Art. New York: Routledge.

Wagstaff, G. 1999. What is Acoustic Ecology's 'Ecology'. Soundscape Newsletter 9 , wfae.net. 